\title{
TOTAL PROHIBITION OF SMOKING BUT NOT PARTIAL RESTRICTION EFFECTIVELY REDUCED EXPOSURE TO TOBACCO SMOKE AMONG RESTAURANT WORKERS IN FINLAND
}

\author{
JERE REIJULA ${ }^{1,2}$, TOM JOHNSSON ${ }^{1}$, SIMO KALEVA ${ }^{1}$, \\ TAPANI TUOMI ${ }^{1}$, and KARI REIJULA ${ }^{1,2}$ \\ ${ }^{1}$ Finnish Institute of Occupational Health (FIOH), Helsinki, Finland \\ ${ }^{2}$ Hjelt Institute, Helsinki, Finland \\ University of Helsinki, Department of Public Health
}

\begin{abstract}
Objectives: To assess work-related exposure to tobacco smoke in Finnish restaurants, a series of nationwide questionnaire surveys were conducted among restaurant workers and the levels of indoor air nicotine concentrations were measured in restaurants. The survey aimed to evaluate the impact of the smoke-free legislation in general and in particular after the total smoking ban launched in 2007. Materials and Methods: In 2003-2010, four national questionnaire surveys were conducted among restaurant workers and the concentration of nicotine in indoor air was measured in different types of restaurants, bars and nightclubs. Results: Between 2003 and 2010, the proportion of restaurant workers reporting occupational exposure to tobacco smoke dropped from $59 \%$ to $11 \%$. Among pub workers, the decrease was from $97 \%$ to $18 \%$ and in workers of dining restaurants from $49 \%$ to $10 \%$, respectively. The median concentration of nicotine in indoor air of all restaurants decreased from $11.7 \mu \mathrm{g} / \mathrm{m}^{3}$ to $0.1 \mu \mathrm{g} / \mathrm{m}^{3}$. The most significant decrease was detected in pubs where the decrease was from $16.1 \mu \mathrm{g} / \mathrm{m}^{3}$ to $0.1 \mu \mathrm{g} / \mathrm{m}^{3}$. Among all restaurant workers, in 2003-2010 the prevalence of daily smokers was reduced from $39 \%$ to $31 \%$ in men and from $35 \%$ to $25 \%$ in women. Conclusion: Total prohibition of smoking but not partial restriction in restaurants was effective in reducing work-related exposure to tobacco smoke. Strict tobacco legislation may partly be associated with the significant decrease of daily smoking prevalence among restaurant workers.
\end{abstract}

Key words:

Secondhand smoke, Occupational exposure, Prevention, Restaurants

\section{INTRODUCTION}

Exposure to tobacco smoke increases the risk of developing several serious adverse health effects including asthma, respiratory infections, cardiovascular diseases and lung cancer [1-4]. It is also associated with lowered birth weight and premature death [5-7].
Many countries in Europe, Asia, Australia and the Northern America have recently launched strict legislation against smoking in various workplaces including restaurants [8-11]. WHO Framework Convention on Tobacco Control (FCTC) has had a significant global role in actions undertaken to prevent tobacco epidemic

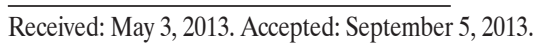

Corresponding author: J. Reijula, Finnish Institute of Occupational Health (FIOH), Topeliuksenkatu 41 a A, FI-00250 Helsinki, Finland (e-mail: reijula@student.uef.fi). 
(WHO 2012) [12]. FCTC Article 8 addresses the adoption and implementation of effective measures to provide protection from exposure to tobacco smoke in domestic and occupational settings.

In Finland, the first Tobacco Act came into force in 1977. In 1995, smoking was forbidden in workplaces, excluding restaurants. In 2000, restaurants were included in the Tobacco Act, with the exception that a proportion of customer spaces could be reserved for smoking customers. Next, the restrictions proceeded gradually, until the Ministry of Social Affairs and Health renewed the legislation in 2005, the Parliament enacted the reform in 2006 and the restaurants had to obey the regulations of the Act beginning June 2007. The legislation allowed restaurants that had made significant changes to their ventilation system to apply for an extension period to continue functioning according to the previous legislation until June, 2009. Then, all restaurants had to totally prohibit smoking in areas for customers. However, restaurants can apply for a permission to build a separate room for smoking customers, which has to fulfill strict ventilation regulations. Smoke must not spread from the smoking room and serving is not allowed in this space.

The present national survey assesses the whole process of a gradual introduction of the smoke-free legislation in Finland. From 1999 to 2010, altogether six national questionnaire surveys were conducted among restaurant workers along with seven indoor air measurement surveys in restaurants of three municipalities to assess the impact of tobacco legislation on restaurant workers' exposure to tobacco smoke $[13,14]$. The present study focuses on the impact of the partial restriction and especially the total ban of smoking in restaurants, which was launched in 2007. Additionally, a comparison between the time period of the partial prohibition (1999-2004 and 2004-2007) and the total prohibition (since 2007) is presented in the report.

\section{MATERIALS AND METHODS}

\section{Questionnaire}

The total workforce in the hospitality industry in Finland varied between 47918 and 53062 individuals in 1999-2010 (Statistics Finland, 2012). Out of them approximately 75$85 \%$ belonged to the national workers union (the Service Union United, PAM).

The follow-up survey consisted of individual cross-sectional surveys. The present study reports the results of them. The data from the first two have been reported earlier [14]. In each annual survey the "target group" was the group of restaurant workers belonging to the restaurant workers union from whom a random sample of 3000 restaurant workers was identified. The questionnaires were sent and returned by mail. In 2003, the questionnaire was re-sent to those who did not respond to the first one. In subsequent years no second attempt was made.

Altogether 6 surveys including questionnaire surveys in restaurants were conducted between the years 1999-2010. In the present study, the data concerning the questionnaires from 2003-2010 were evaluated to assess the impact of the latest reform in Tobacco Act concerning restaurant work and the launch of the total smoking ban in 2007. The first survey was carried out in 2003, four years before the total smoking ban and the second in 2007, five months before the total ban. The third survey in 2009 was conducted almost two years and the last survey in 2010 three years after the launch of the total smoking ban in restaurants.

In each survey, the member list of restaurant workers was updated so that those who retired, were unemployed or who worked in a different sector were excluded from the group. The questionnaires aimed at collecting the participants' background information, smoking habits, restrictions on smoking at their workplace, occupational exposure and symptoms related to tobacco smoke.

The questions concerning respondents' smoking habits included questions on daily smoking and the number of 
cigarettes smoked daily, and the smoking history assessment of exposure to tobacco smoke included the following questions:

- "how many hours per day are you exposed to tobacco smoke at work?",

- "is smoking allowed in your workplace (bar and restaurant)?",

- "in what areas is smoking allowed?",

- "are there designated areas or tobacco rooms for smoking?",

- "if yes, does the smoke spread elsewhere?",

- "is smoking allowed in break rooms recreation for workers?".

Each year the questionnaire and the measurement were the same as in the previous years.

\section{Measurement of nicotine in indoor air}

Altogether seven surveys including nicotine measurements in restaurants were conducted between the years 19992010. The data concerning the measurements in 19992004 had been published elsewhere [16]. These results can be seen in Figure 2.

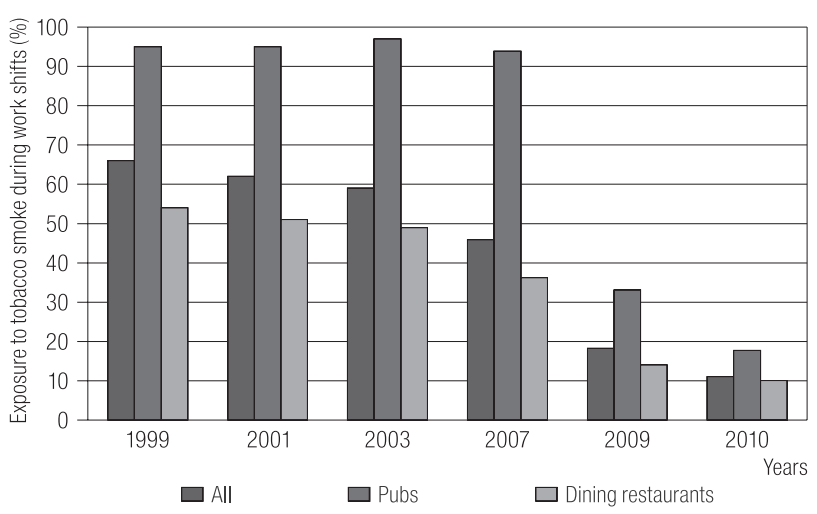

Bars represent 1999 - no ban.

2000-2007 - partial restrictions.

2007-2010 - total restrictions.

Fig. 1. Work-related exposure to tobacco smoke among Finnish restaurant workers according to questionnaire surveys conducted in 1999-2010

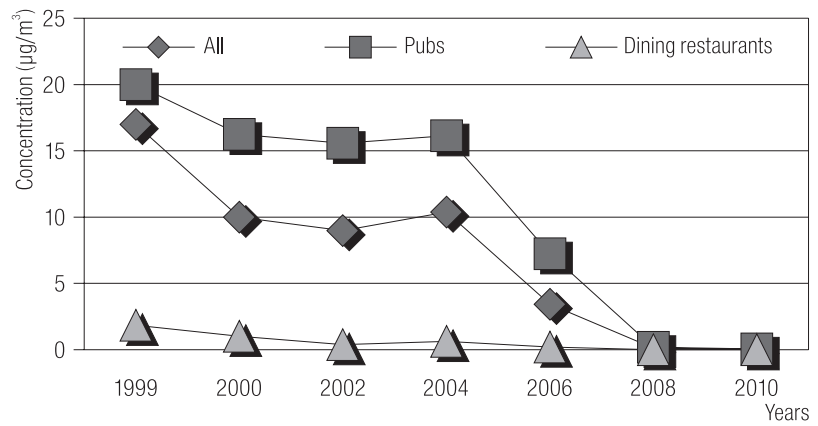

Abbreviations as in Figure 1.

Fig. 2. Median concentration of indoor air nicotine in restaurants in 1999-2010

Exposure to tobacco smoke was assessed by measuring the concentration of nicotine in the indoor air of restaurants and bars. Nicotine was used as the indicator for tobacco smoke because it had successfully been used in previous surveys in assessing work-related exposure to tobacco smoke [15-18].

The number of restaurants participating in the present survey is shown in Table 1. The indoor air measurements were carried out during the period in which indoor heating is generally turned on, namely the fall and winter seasons. This enabled the comparison of results, because the ventilation was dependent solely on mechanical ventilation present in all establishments. Historically, the frequency and degree of customer smoking differed depending on the clientele [16]. Therefore, three different types of premises were selected, i.e. restaurants, pubs and nightclubs. In addition, employees mainly working in bar counter service were considered separately from others (Table 1).

The category of pubs in this paper includes typical pubs, bars and taverns. The category of nightclubs comprises also discos, and the category of restaurants, for the purpose of this study, means locations where food was the main attraction. The establishments were selected from three cities located in different parts of the country: Helsinki, Lappeenranta and Jyväskylä. They were chosen after consultation with hospitality 
Table 1. Nicotine concentrations in indoor air measured from fixed points in restaurants and reported exposure to tobacco smoke at work

\begin{tabular}{|c|c|c|c|c|c|}
\hline \multirow{2}{*}{ Nicotine in indoor air } & \multirow{2}{*}{$\begin{array}{l}\text { Dining } \\
\text { restaurant }\end{array}$} & \multicolumn{3}{|c|}{ Type of venue } & \multirow{2}{*}{ Total } \\
\hline & & pubs & nightclubs & bar desks & \\
\hline \multicolumn{6}{|l|}{2004} \\
\hline measurements (n) & 20.0 & 78.0 & 61.0 & 64.0 & 223.0 \\
\hline \multicolumn{6}{|l|}{ nicotine concentration $\left(\mu \mathrm{g} / \mathrm{m}^{3}\right)$} \\
\hline median & 0.6 & 16.1 & 10.9 & 10.4 & 11.7 \\
\hline $\min$. & 0.0 & 0.6 & 0.2 & 0.1 & 0.1 \\
\hline $\max$ & 11.2 & 172.1 & 133.4 & 133.4 & 172.1 \\
\hline rep. exp. (2003) (\%) & 49.0 & 97.0 & 95.0 & 97.0 & 59.0 \\
\hline \multicolumn{6}{|l|}{2006} \\
\hline measurements (n) & 24.0 & 71.0 & 64.0 & 67.0 & 226.0 \\
\hline \multicolumn{6}{|l|}{ nicotine concentration $\left(\mu \mathrm{g} / \mathrm{m}^{3}\right)$} \\
\hline median & 0.2 & 7.2 & 5.2 & 4.2 & 5.0 \\
\hline $\min$. & 0.0 & 0.0 & 0.1 & 0.0 & 0.0 \\
\hline $\max$ & 4.3 & 99.3 & 132.7 & 132.7 & 132.7 \\
\hline rep. exp. (2007) (\%) & 36.0 & 94.0 & 91.0 & 90.0 & 46.0 \\
\hline \multicolumn{6}{|l|}{2008} \\
\hline measurements $(\mathrm{n})$ & 0.0 & 62.0 & 43.0 & 60.0 & 165.0 \\
\hline \multicolumn{6}{|l|}{ nicotine concentration $\left(\mu \mathrm{g} / \mathrm{m}^{3}\right)$} \\
\hline median & 0.0 & 0.2 & 0.1 & 0.2 & 0.2 \\
\hline $\min$. & 0.0 & 0.0 & 0.0 & 0.0 & 0.0 \\
\hline $\max$ & 0.0 & 4.1 & 3.7 & 4.1 & 4.1 \\
\hline rep.exp. (2009) (\%) & 14 & 33.0 & 29.0 & 30.0 & 18.0 \\
\hline \multicolumn{6}{|l|}{2010} \\
\hline measurements (n) & 0.0 & 53.0 & 30.0 & 33.0 & 116.0 \\
\hline \multicolumn{6}{|l|}{ nicotine concentration $\left(\mu \mathrm{g} / \mathrm{m}^{3}\right)$} \\
\hline median & 0.0 & 0.1 & 0.0 & 0.1 & 0.1 \\
\hline $\min$. & 0.0 & 0.0 & 0.0 & 0.0 & 0.0 \\
\hline $\max$ & 0.0 & 4.8 & 0.7 & 0.6 & 4.8 \\
\hline rep. $\exp (2010)(\%)$ & 10.0 & 18.0 & 24.0 & 17.0 & 11.0 \\
\hline
\end{tabular}

min. - minimum; max - maximum.

Rep.exp. - respondents reporting exposure (at least 1 hour per work shift).

management professionals with local knowledge of the cities studied.

The collection of indoor air samples, measurements and laboratory analyses had been described in details earlier [16]. Briefly, samples were collected from the same sampling locations during each monitoring period where possible. Measurements were conducted at three to five locations per establishment. The criteria for the 
sampling locations were as follows: the location represents the entire space as fully as possible, at least one at the bar counter(s), at least one in the smoke-free and one in the smoking section (not applicable after 2007). Air sampling was carried out for a 4-hour period during peak hours and it was performed twice at each selected establishment.

The air monitor consisted of a sampling pump collecting air at $100 \mathrm{~cm}^{3} \times \mathrm{min}^{-1}$ through a stainless steel tube packed with Tenax adsorbent. The sample analysis has been described in a previous publication [19]. Briefly, the samples were desorbed at $300^{\circ} \mathrm{C}$ and analyzed for nicotine by thermodesorption - gas chromatography - mass spectrometry. The measured nicotine concentration represents the average concentration during the $4 \mathrm{~h}$ period. For samples with nicotine concentrations below the limit of quantitation $\left(0.05 \mu \mathrm{g} / \mathrm{m}^{3}\right)$, we used $0.025 \mu \mathrm{g} / \mathrm{m}^{3}$ for calculations.

The Finnish Institute of Occupational Health (FIOH), Client Services is accredited by the Finnish Accreditation Service (FINAS).

\section{Statistical analyses}

The individual nominal scale answers of the data were examined with the use of percentages, and cross-tabulating them according to, for example, sex, profession, age and position as a superior. Medians were calculated for variables that received a numeric value and were compared across different groups. Binominal tests and $\mathrm{Chi}^{2}$ tests were used to analyse the survey data, using SAS Statistical software, version 9.1 (SAS Institute Inc, Cary, North Carolina, USA).

\section{RESULTS}

\section{Respondent characteristics}

The details of respondents' background are presented in Table 2. The response rate varied between $25 \%$ and $56 \%$. During the follow-up, the percentage of waiters and waitresses increased from $30 \%$ to $60 \%$, while the proportion of chefs and cooks decreased from $39 \%$ to $6 \%$. The average age varied between 38 and 41 years in 2003-2010. The respondents' length of work experience was on average 15 years in 2003 and 19 years in 2010.

Each year, the respondents represented well the general population of the union members, compared with the information available on the place of residence, gender, age, and educational background of PAM members. For instance, according to official registers (Statistics Finland) in 2003 the percentage of female workers was $80 \%$ in the Restaurant and Hotel Union, while it was the same in the

Table 2. Background information from questionnaire surveys

\begin{tabular}{lrrrr}
\hline \multicolumn{1}{c}{ Background information } & 2003 & 2007 & 2009 & 2010 \\
\hline Participants (n) & 1690 & 1008 & 805 & 741 \\
Response rate (\%) & 56 & 35 & 27 & 25 \\
Women (\%) & 80 & 83 & 86 & 84 \\
Superiors (\%) & 27 & 27 & 31 & 27 \\
Average age (years) & 38 & 38 & 38 & 41 \\
Experience (years) & 15 & 15 & 16 & 19 \\
Daily smokers (\%) & & & & \\
$\quad$ all participants & 36 & 33 & 30 & 26 \\
women & 35 & 31 & 31 & 25 \\
men & 39 & 39 & 30 & 31 \\
\hline
\end{tabular}


Table 2. Background information from questionnaire surveys - cont.

\begin{tabular}{|c|c|c|c|c|}
\hline Background information & 2003 & 2007 & 2009 & 2010 \\
\hline \multicolumn{5}{|l|}{ Educational background $(\%)$} \\
\hline no professional degree & 19 & 14 & 22 & 24 \\
\hline professional or institutional level & 77 & 85 & 77 & 75 \\
\hline university level & 4 & 2 & 1 & 1 \\
\hline \multicolumn{5}{|l|}{ Profession $(\%)$} \\
\hline waiter/waitress & 30 & 32 & 53 & 60 \\
\hline chef/cook & 39 & 36 & 7 & 6 \\
\hline manager/equivalent & 16 & 16 & 22 & 20 \\
\hline bartender & 6 & 6 & 9 & 9 \\
\hline other & 9 & 10 & 9 & 5 \\
\hline \multicolumn{5}{|l|}{ Workplace (\%) } \\
\hline dining restaurant & 72 & 73 & 64 & 63 \\
\hline nightclub & 10 & 8 & 11 & 12 \\
\hline pub & 10 & 10 & 18 & 17 \\
\hline café & 8 & 9 & 7 & 8 \\
\hline
\end{tabular}

present survey. In 2010, the figures were 79\% and $84 \%$, respectively. In $2003,80 \%$ of all restaurant workers had a professional, institutional or university level degree while $18 \%$ of them had no professional degree (Statistics Finland). In the present study, in 2003, the numbers were $81 \%$ and $19 \%$ respectively. In $2010,78 \%$ of restaurant workers had a professional, institutional or university level degree, while $22 \%$ did not have any professional degree (Statistics Finland). In the present survey, in 2010, the proportion was $76 \%$ and $24 \%$, respectively.

\section{Smoking and exposure to tobacco smoke}

The prevalence of daily smokers decreased from $36 \%$ to $26 \%$ between 2003 and 2010 (Table 2). Smoking was more common among men. In 2003, altogether 39\% of men and $35 \%$ of women smoked daily, while in 2010 the figures were $31 \%$ and $25 \%$, respectively.

Between 2003-2010, the prevalence of restaurant workers exposed to tobacco smoke at least 1 hour per work shift decreased from $59 \%$ to $11 \%$ (Table 1). The exposure to tobacco smoke was more common among pub and nightclub workers than in workers of dining restaurants. Between 2003-2010, the percentage of pub workers exposed to tobacco smoke for at least 1 hour a day, decreased from $97 \%$ to $18 \%$, and that of workers in dining restaurants from $49 \%$ to $10 \%$.

\section{Measurement of nicotine in indoor air}

Between 2004-2010, the maximum nicotine concentration in indoor air decreased from $172.1 \mu \mathrm{g} / \mathrm{m}^{3}$ to $4.8 \mu \mathrm{g} / \mathrm{m}^{3}$, and the minimum concentration from $0.08 \mu \mathrm{g} / \mathrm{m}^{3}$ to below the quantitation limit of the method $\left(0.05 \mu \mathrm{g} / \mathrm{m}^{3}\right)$. Measurements in dining restaurants in 2004 and 2006 showed nicotine and 3-ethenyl pyridine concentrations below the quantitation limit. Therefore, measurements were not performed in dining restaurants in 2008 and 2010.

The median nicotine concentration in indoor air of all establishments decreased from $11.7 \mu \mathrm{g} / \mathrm{m}^{3}$ to $0.1 \mu \mathrm{g} / \mathrm{m}^{3}$, excluding the measurements in dining restaurants for the years 2008 and 2010. 
The median nicotine concentrations were the highest in pubs, varying from $16.1 \mu \mathrm{g} / \mathrm{m}^{3}$ in 2004 to $0.1 \mu \mathrm{g} / \mathrm{m}^{3}$ in 2010. There was a significant reduction of nicotine concentration in all restaurants between the measurements in 2004 and 2008, while the median concentration first decreased from $11.7 \mu \mathrm{g} / \mathrm{m}^{3}$ to $5 \mu \mathrm{g} / \mathrm{m}^{3}$ (in 2006) and then to $0.2 \mu \mathrm{g} / \mathrm{m}^{3}$ (in 2008). In 2010, the median concentration of nicotine remained on the level of $0.1 \mu \mathrm{g} / \mathrm{m}^{3}$.

When comparing the data of questionnaire surveys and nicotine measurements, both the prevalence of workers exposed to tobacco smoke and median concentration of nicotine in indoor air, were the highest in all surveys among pub workers and lowest among workers in dining restaurants. According to both questionnaire surveys and nicotine measurements, a significant decrease of exposure to tobacco smoke could be demonstrated over time.

\section{DISCUSSION}

The present follow-up study is the first nationwide survey undertaken to assess the impact of tobacco legislation consisting both the partial and the total prohibition of smoking in restaurants. The assessment was carried out by using questionnaire surveys, accompanied by measurements of indoor air nicotine concentrations in restaurants in three municipalities from different parts of the country. This gives a reliable estimation of the current situation regarding restaurant workers' exposure to tobacco smoke at work and it also makes it possible to evaluate if the decrease of exposure to tobacco smoke continued during the follow up period and exposure levels remained low. The present study shows the impact of gradually proceeding tobacco-free legislation concerning bars and restaurants.

In the present study, we focus on the pre- and post-ban situation in Finnish restaurants. The total ban on smoking in restaurants was proposed by the Ministry of Social Affairs and Health (in 2005). The Parliament enacted renewed tobacco legislation with the total prohibition of smoking in restaurants in 2006 which restaurants had to obey beginning June 2007. In our earlier studies, we had shown that tobacco legislation with partial prohibition of smoking in restaurants only slowly decreased exposure to tobacco smoke (in 1999-2004) [13,14].

Between 2003 and 2007, before the total prohibition, exposure to tobacco smoke began to decrease according to both the questionnaire surveys and indoor air measurements. This may be due to the knowledge among restaurant owners that the Ministry was already preparing the total ban on smoking in restaurants. Therefore, the restaurants began to make the arrangements to totally prohibit smoking in their areas for customers. A similar decrease in exposure to tobacco smoke was also demonstrated in Finland before 1995 when strict tobacco legislation was launched for all other workplaces [15].

By integrating the results of questionnaire surveys with the outcome of measured air samples it was possible to assess the exposure to tobacco smoke from two directions. Thus, we are able to get data not only as regards the duration of exposure and the number of affected workers, but also an estimation of the concentration of an inhaled substance. This can help us to assess the severity of the exposure to tobacco smoke by comparing the reported time of total exposure with the indoor air nicotine concentration measured at various types of restaurants (e.g. restaurants, pubs and nightclubs).

In a recent study, exposure to tobacco smoke at work was assessed by questionnaire surveys and measuring nicotine concentration in indoor air [15]. In accordance with our findings, they found a positive correlation between the measured indoor nicotine concentration and self-reported exposure to tobacco smoke. Another recent study suggests that a self-reported exposure to tobacco smoke is a valid method for evaluating workers' exposure to tobacco smoke [20]. Similarly, our data show that the measured nicotine concentrations were the highest in the type of 
establishment where the workers also reported the longest duration of exposure to tobacco smoke.

Our study participants are members of the national Service Union United (PAM) that unites approximately $75-85 \%$ of all employees in the hospitality industry in Finland. Thus, the present material represents a significant part of all Finnish restaurant workers. Most PAM members work in restaurants that belong to the national Tourism and Restaurant Services Union. This all may have an influence on the collected data because adherence to tobacco legislation may be better in establishments belonging to the national association compared to non-members.

The response rate of participants in the present questionnaire surveys remains fairly low (25-59\%). The hospitality industry has often been one of the fields of industry in which researchers have had difficulties in achieving acceptable response rates. This may be due to the frequent rotation of the restaurant workers, leading to difficulties in reaching them for questionnaire surveys by mail. Nevertheless, the demographic information, years of experience and other details of participants in the present study closely reflected the average population of restaurant workers in this country. Additionally, the variation in the response rates between different years is also due to annual resources available for questionnaire surveys. In 2003, there was an opportunity to re-send the questionnaires to those who failed to answer the first letter that was sent. This explains the higher response rate in 2003.

The low response rate may have had an influence on the smoking prevalence found in the present study. The prevalence of daily smokers decreased from $36 \%$ to $26 \%$ between 2003 and 2010. This decrease may partly be explained by the fact that non-smoking employees in restaurants which obey the strict tobacco legislation might have been more active in responding to the present survey. On the other hand, the decrease in the percentage of daily smokers can also be due to the strict tobacco legislation, which may have helped them in quitting smoking. In addition, changes in public opinion and attitudes towards smoking in general may have had a positive impact on smoking prevalence.

The ratio between chefs and waiters changed during the follow-up. This may be due to the decreased interest among chefs and cooks to respond since their worksite (kitchen) had been smoke-free for a significantly longer period of time compared to worksites of waiters. The change in the ratio may have had an impact on the present data. However, the data concerning exposure to tobacco smoke is presented separately for different professions. Thus, it should not cause any significant bias in the present follow-up.

Between 1999-2004, Finnish tobacco legislation with the partial restriction of smoking in restaurants only slowly decreased the occupational exposure to tobacco smoke in restaurants (Figure 1 and 2) [14]. The reform in the legislation prepared by the Ministry of Social Affairs and Health in 2005,enacted by the Parliament in 2006 with a total smoking ban beginning in 2007 in restaurants effectively reduced work-related exposure to tobacco smoke in restaurants. Interestingly, the decrease of exposure seemed to escalate after 2004 soon after the restaurants found out that the Ministry was planning to introduce the total smoking ban in restaurants.

Several studies have shown that total smoke-free legislation is highly effective in reducing indoor tobacco smoke levels. A recent study carried out in Germany found a significant reduction of exposure to tobacco smoke in bars and restaurants. Concentration of fine particles $\left(\mathrm{PM}_{2.5}\right)$ decreased by $87 \%$ in coffee bars, $89 \%$ in restaurants, $66 \%$ in bars, and $91 \%$ in discotheques before and after the introduction of smoke-free legislation [21]. The concentrations were substantially higher in venues which allowed smoking in the whole venue or in a designated smoking room compared to venues which were completely smoke-free. 
This study clearly demonstrates that when smoking is allowed inside the premises, such measures as ventilation or designated smoking areas are not sufficient enough in preventing tobacco smoke from spreading to areas, which should be smoke-free.

Another study performed in Scottish pubs reported a reduction in PM (2.5) levels from an average of $246 \mu \mathrm{g} / \mathrm{m}^{3}$ to $20 \mu \mathrm{g} / \mathrm{m}^{3}$ after smoke-free legislation had been enacted [22].

Abundant evidence shows that exposure to tobacco smoke is harmful to health since it causes cardiovascular and respiratory diseases [3,23]. A recent study carried out in Scotland assessed the effectiveness of smoke-free legislation by examining changes in the health of bar workers [24]. The results showed that there were significantly fewer respiratory and sensory symptoms after the workplaces had become smoke-free. The percentage of workers reporting any respiratory symptoms decreased from $69 \%$ to $57 \%$ while the percentage of those with sensory symptoms decreased from $75 \%$ to $64 \%$.

Another study from Spain shows that the prevalence of respiratory symptoms declined significantly (by $71.9 \%$; $\mathrm{p}<0.05$ ) among non-smoking workers in venues that became smoke-free [25]. Furthermore, there was no significant decrease in the prevalence of respiratory symptoms among non-smoking workers in restaurants which had not prohibited smoking entirely or had introduced only partial restrictions in their restaurant premises. This shows the significance of effective tobacco legislation that can protect workers from exposure to tobacco smoke and ensures benefits to the public health as well.

Previous studies from Scotland found that the percentage of bar workers with respiratory and sensory symptoms decreased from $79.2 \%(\mathrm{~N}=61)$ to $53.2 \%(\mathrm{~N}=41)$ and $46.8 \%(\mathrm{~N}=38)$ during one and two months after the total smoke-free policy had been launched [26]. In this Scottish study, asthmatic bar workers suffered less often from airway inflammation and the quality-of-life scores increased after the total prohibition of smoking in bars. In addition, a Norwegian study assessed cross-shift changes in the lung function by measuring a decrease in forced vital capacity (FVC) before and after the smoke-free ban. They found a significant decrease in the reduction of FVC during the studied period [27]. In our previous study among restaurant workers, the prevalence of respiratory symptoms decreased from $18 \%$ to $4 \%(\mathrm{p}<0.0001)$ and the prevalence of eye symptoms from $23 \%$ to $6 \%$ ( $p<0.0001$ ) after the legislation that prohibited smoking in restaurants had been launched [28].

A recent study from New Zealand evaluated the impact of a national smoke-free law by assessing the exposure to tobacco smoke [15], smoking-related behaviors and economic impacts [29]. The results showed evidence of high compliance in bars and pubs as the self-reported exposure to tobacco smoke dropped from 20\% to 8\% between 2003 and 2006. During this time period, the indoor air quality improved significantly in these hospitality venues. Moreover, the authors found that the strict tobacco legislation had a neutral economical impact in tourist and hospitality sectors in New Zealand.

Questionnaire surveys and measurements of nicotine levels in indoor air combined together are reliable and feasible methods for assessing exposure to work-related exposure to tobacco smoke. A decrease in the prevalence of daily smoking among restaurant workers in the preset study may partly be explained by the strict tobacco legislation.

\section{CONCLUSION}

The present findings show that strict tobacco legislation, which totally prohibits smoking in restaurants, is effective in protecting restaurant workers from exposure to tobacco smoke. According to the present survey, since 1999, the decline in occupational exposure to tobacco smoke also continued throughout the follow-up period and the levels of exposure remained low. 


\section{REFERENCES}

1. Janson C, Chinn S, Jarvis D, Zock JP, Torén K, Burney P. European Community Respiratory Health Survey. Effect of passive smoking on respiratory symptoms, bronchial responsiveness, lung function, and total serum $\operatorname{IgE}$ in the European Community Respiratory Health Survey: A cross-sectional study. Lancet. 2001;358(9299):2103-9, http://dx.doi. org/10.1016/S0140-6736(01)07214-2.

2. Oberg M, Jaakkola MS, Woodward A, Peruga A, PrüssUstün A. Worldwide burden of disease from exposure to second-hand smoke: A retrospective analysis of data from 192 countries. Lancet. 2011;377(9760):139-46, http://dx.doi. org/10.1016/S0140-6736(10)61388-8.

3. IARC. Monographs on the Evaluation of Carcinogenic Risks to Human. VOLUME 83. Tobacco Smoke and Involuntary Smoking. Lyon: IARC; 2004.

4. U.S. Department of Health and Human Services. The Health Consequences of Involuntary Exposure to Tobacco Smoke: A Report of the Surgeon General. Atlanta (GA): U.S. Department of Health and Human Services, Centers for Disease Control and Prevention, Coordinating Center for Health Promotion, National Center for Chronic Disease Prevention and Health Promotion, Office on Smoking and Health; 2006.

5. Klonoff-Cohen HS, Edelstein SL, Lefkowitz ES, Srinivasan IP, Kaegi D, Chang JC, et al. The effect of passive smoking and tobacco exposure through breast milk on sudden infant death syndrome. JAMA. 1995;273(10):795-8, http:// dx.doi.org/10.1001/jama.1995.03520340051035.

6. Windham GC, Eaton A, Hopkins B. Evidence for an association between environmental tobacco smoke exposure and birthweight: a meta-analysis and new data. Paediatr Perinat Epidemiol. 1999;13:35-57, http://dx.doi.org/10.1046/j.13653016.1999.00150.x.

7. Leonardi-Bee J, Smyth A, Britton J, Coleman T. Environmental tobacco smoke and fetal health: systematic review and meta-analysis. Arch Dis Child Fetal Neonatal Ed. 2008;93(5): F351-61, http://dx.doi.org/10.1136/adc.2007.133553.
8. Mons U, Nagelhout GE, Allwright S, Guignard R, van den Putte B, Willemsen MC, et al. Impact of national smoke-free legislation on home smoking bans: findings from the International Tobacco Control Policy Evaluation Project Europe Surveys. Tob Control. 2013;22(e1):e2-9. doi:10.1136/ tobaccocontrol-2011-050131.

9. Levy DT, Benjakul S, Ross H, Ritthiphakdee B. The role of tobacco control policies in reducing smoking and deaths in a middle income nation: results from the Thailand SimSmoke simulation model. Tob Control. 2008;17(1):53-9, http://dx.doi.org/10.1136/tc.2007.022319.

10. Borland R, Yong HH, Siahpush M, Hyland A, Campbell S, Hastings G, et al. Support for and reported compliance with smoke-free restaurants and bars by smokers in four countries: findings from the International Tobacco Control (ITC) Four Country Survey. Tob Control. 2006;15 Suppl 3:iii34-41, http://dx.doi.org/10.1136/tc.2004.008748.

11. Farrelly MC, Nonnemaker JM, Chou R, Hyland A, Peterson KK, Bauer UE. Changes in hospitality workers' exposure to secondhand smoke following the implementation of New York's smoke-free law. Tob Control. 2005;14(4): 236-41, http://dx.doi.org/10.1136/tc.2004.008839.

12. WHO FCTC. 2012 Global Progress Report on implementation of the WHO Framework Convention on Tobacco Control. Geneva: WHO Press, World Health Organization; 2012.

13. Johnsson T, Tuomi T, Hyvärinen M, Svinhufvud J, Rothberg M, Reijula K. Occupational exposure of non-smoking restaurant personnel to environmental tobacco smoke in Finland. Am J Ind Med. 2003;43(5):523-31, http://dx.doi. org/10.1002/ajim.10207.

14. Reijula JP, Reijula KE. The impact of Finnish tobacco legislation on restaurant workers' exposure to tobacco smoke at work. Scand J Public Health. 2010;38(7):724-30, http:// dx.doi.org/10.1177/1403494810379168.

15. Heloma A, Kähkönen E, Kaleva S, Reijula K. Smoking and exposure to tobacco smoke at medium-sized and large-scale workplaces. Am J Ind Med. 2000;37(2):214-20, http://dx.doi. 
org/10.1002/(SICI)1097-0274(200002)37:2<214::AIDAJIM7>3.3.CO;2-Q.

16. Johnsson T, Tuomi T, Riuttala H, Hyvärinen M, Rothberg M, Reijula K. Environmental tobacco smoke in Finnish restaurants and bars before and after smoking restrictions were introduced. Ann Occup Hyg. 2006;50(4):331-41, http://dx.doi. org/10.1093/annhyg/mel011.

17. Vainiotalo S, Väänänen V, Vaaranrinta R. Measurement of 16 volatile organic compounds in restaurant air contaminated with environmental tobacco smoke. Environ Res. 2008;108(3):280-8， http://dx.doi.org/10.1016/j.envres.2008.07.020.

18. Wipfli H, Avila-Tang E, Navas-Acien A, Kim S, Onicescu G, Yuan J, et al. Secondhand smoke exposure among women and children: evidence from 31 countries. Am J Public Health. 2008;98(4):672-9, http://dx.doi.org/10.2105/ AJPH.2007.126631.

19. Rothberg M, Heloma A, Svinhufvud J, Kähkönen E, Reijula K. Measurement and analysis of nicotine and other VOCs in indoor air as an indicator of passive smoking. Ann Occup Hyg. 1998;42(2):129-34, http://dx.doi.org/10.1093/ annhyg/42.2.129.

20. Willemsen MC, Brug J, Uges DR, Vos de Wael ML. Validity and reliability of self-reported exposure to environmental tobacco smoke in work offices. J Occup Environ Med. 1997;39(11):1111-4, http://dx.doi. org/10.1097/00043764-199711000-00012.

21. Gleich F, Mons U, Pötschke-Langer M. Air contamination due to smoking in German restaurants, bars, and other venues-before and after the implementation of a partial smoking ban. Nicotine Tob Res. 2011;13(11):1155-60, http:// dx.doi.org/10.1093/ntr/ntr099.

22. Semple S, Creely KS, Naji A, Miller BG, Ayres JG. Secondhand smoke levels in Scottish pubs: The effect of smoke-free legislation. Tob Control 2007;16(2):127-32, http://dx.doi. org/10.1136/tc.2006.018119.
23. Lightwood JM, Glantz SA. Declines in acute myocardial infarction after smoke-free laws and individual risk attributable to secondhand smoke. Circulation. 2009;120(14):1373-9, http://dx.doi.org/10.1161/CIRCULATIONAHA.109.870691.

24. Ayres JG, Semple S, MacCalman L, Dempsey S, Hilton S, Hurley JF, et al. Bar workers' health and environmental tobacco smoke exposure(BHETSE): symptomatic improvement in bar staff following smoke-free legislation in Scotland. Occup Environ Med. 2009;66(5):339-46, http://dx.doi. org/10.1136/oem.2008.040311.

25. Fernández E, Fu M, Pascual JA, López MJ, Pérez-Ríos M, Schiaffino A, et al. Impact of the Spanish smoking law on exposure to second-hand smoke and respiratory health in hospitality workers: a cohort study. PLoS One. 2009;4(1):e4244, http://dx.doi.org/10.1371/journal.pone.0004244.

26. Menzies D, Nair A, Williamson PA, Schembri S, Al-Khairalla MZ, Barnes M, et al. Respiratory symptoms, pulmonary function, and markers of inflammation among bar workers before and after a legislative ban on smoking in public places. JAMA. 2006;296(14):1742-8, http://dx.doi. org/10.1001/jama.296.14.1742.

27. Skogstad M, Kjaerheim K, Fladseth G, Gjølstad M, Daae HL, Olsen R, et al. Cross shift changes in lung function among bar and restaurant workers before and after implementation of a smoking ban. Occup Environ Med. 2006;63(7):482-7, http://dx.doi.org/10.1136/oem.2005.024638.

28. Reijula JP, Johnsson TS, Kaleva PS, Reijula KE. Exposure to tobacco smoke and prevalence of symptoms decreased among Finnish restaurant workers after the smoke-free law. Am J Ind Med. 2012;55(1):37-43, http://dx.doi.org/10.1002/ ajim.21006.

29. Edwards R, Thomson G, Wilson N, Waa A, Bullen C, O'Dea D, et al. After the smoke has cleared: evaluation of the impact of a new national smoke-free law in New Zealand. Tob Control. 2008;17(1):e2, http://dx.doi.org/10.1136/ tc.2007.020347.

This work is available in Open Access model and licensed under a Creative Commons Attribution-NonCommercial 3.0 Poland License - http://creativecommons.org/ licenses/by-nc/3.0/pl/deed.en. 